\section{Prevalence of Helicobacter pylori infection in dyspeptic patients in Iran}

\author{
Leila Shokrzadeh, ${ }^{1}$ Kaveh Baghaei, ${ }^{1}$ \\ Yoshio Yamaoka, ${ }^{2,3}$ Seiji Shiota, ${ }^{2}$ \\ Dariush Mirsattari, ${ }^{1}$ \\ Asma Porhoseingholi, ${ }^{1}$ \\ Mohammad Reza Zali1
}

${ }^{1}$ Research Center for Gastroenterology and Liver Diseases, Shahid Beheshti University of Medical Science, Tehran, Iran; ${ }^{2}$ Department of Environmental and Preventive Medicine, Oita University Faculty of Medicine, Yufu, Japan; ${ }^{3}$ Department of Gastroenterology, Baylor College of Medicine, Houston, Texas USA

\section{Abstract}

Although Helicobacter pylori (H. pylori) infection has been known to be associated with several upper gastrointestinal disorders such as peptic ulcer and gastric cancer, the relationship between $H$. pylori infection and dyspeptic symptoms remains controversial. Furthermore, it is still not clear which factors are associated with $H$. pylori infection in the Iranian population. We investigated the prevalence of $H$. pylori infection in dyspeptic patients and factors associated with $H$. pylori infection in the Iranian population. In this cross-sectional study, 303 patients with dyspeptic symptoms underwent endoscopy. Clinical data and a questionnaire about gastrointestinal symptoms were collected from each patient. $H$. pylori status was evaluated by histological examination. Among the 303 patients, $263(86.8 \%)$ were found to be positive for $H$. pylori. The prevalence of $H$. pylori infection decreased significantly with age. There was no difference in the prevalence of $H$. pylori infection between the patients with and those without a family history of gastroduodenal diseases. Among 250 patients with abdominal pain, 219 (87.6\%) were infected with $H$. pylori. Among 211 patients with epigastric abdominal pain, 185 (87.7\%) were infected with $H$. pylori. It was observed that belching was significantly associated with $H$. pylori infection $(\mathrm{P}=0.03)$. Dyspepsia triggered by the consumption of tea was higher in $H$. pylori-positive patients than in $H$. pylori-negative patients $(\mathrm{P}=0.03)$. The prevalence of $H$. pylori infection in dyspeptic patients was quite high in Iran. Belching and dyspepsia triggered by tea consumption was related with $H$. pylori infection.

\section{Introduction}

Helicobacter pylori (H. pylori) are Gramnegative bacteria that colonize gastric mucosa. They are the most important etiological agents for peptic ulcer disease, gastric carcinoma and mucosa-associated lymphoid tissue lymphoma. ${ }^{1-3}$ Infection with $H$. pylori mainly occurs in early childhood and shows life-long persistence in most infected individuals., ${ }^{4,5}$ Because of the high risk of $H$. pylori transmission from adults to children, especially from parents in a family setting, prevalence of $H$. pylori in childhood is related to its prevalence in adults. 6,7

In addition to the virulence of $H$. pylori, host and environmental factors determine clinical outcome. It has been reported that the prevalence of $H$. pylori infection was related to several of these factors, including socioeconomic status, crowded living conditions, low levels of hygiene, age, geographical region, ethnic group, cigarette and alcohol consumption. ${ }^{8-10}$ Also, prevalence of $H$. pylori infection differs both between and within countries. ${ }^{11,12}$

Although in the Iranian population the prevalence has been reported to range from 57 to $91 \%,{ }^{13-17}$ the factors associated with $H$. pylori infection have not been clarified. In addition, there have been no reports about the prevalence of $H$. pylori infection in dyspeptic patients in Iran.

The aim of this study was to investigate the prevalence of $H$. pylori infection in dyspeptic patients and factors associated with $H$. pylori infection in an Iranian population.

\section{Materials and Methods}

\section{Subjects}

A cross-sectional study was carried out between April 2007 and January 2008. A total of 486 Iranian patients attended the endoscopy unit of the Taleghani Hospital, Shahid Beheshti University, for dyspeptic symptoms such as abdominal pain, anorexia, bloating, and belching. Patients who had received non-steroidal anti-inflammatory drugs, steroids or proton pump inhibitors within the previous three months, any antibiotics within the last month, and previous treatment for $H$. pylori infection were excluded. The remaining 303 patients were enrolled in the study. Of these, 172 (56.7\%) were female and 131 (43.3\%) male; mean age $42.2 \pm 15.5$ years

Clinical data regarding current and past medical history, and family history of peptic
Correspondence: Leila Shokrzadeh, Taleghani Hospital, Parvaneh Ave., Tabnak St., Velenjak, Tehran, Iran.

Tel. +98.9124370314 - Fax: +98.2122432517.

E-mail: l.shokrzadeh@gmail.com

Key words: Helicobacter pylori, clinical symptoms, family history, dyspeptic patients

Acknowledgment: this study was supported by a grant from the Research Center for Gastroenterology and Liver Diseases, Shahid Beheshti University of Medical Science, Tehran, Iran.

Conflict of interests: the authors report no potential conflict of interests.

Received for publication: 9 August 2011.

Revision received: 26 February 2012.

Accepted for publication: 1 March 2012.

This work is licensed under a Creative Commons Attribution NonCommercial 3.0 License (CC BYNC 3.0).

CC Copyright L. Shokrzadeh et al., 2012 Licensee PAGEPress, Italy

Gastroenterology Insights 2012; 4:e8 doi:10.4081/gi.2012.e8

ulcer/gastric cancer were collected for each patient. Patients' demographics, including age, sex, and ethnicity, were also recorded. Gastrointestinal symptoms were evaluated from questionnaires completed by the patients that included questions concerning dyspeptic symptoms and their triggers.

This study was approved by the ethical committee of the Research Center for Gastroenterology and Liver Disease, Shahid Beheshti University, M.C. All patients provided written informed consent.

\section{Evaluation of $H$. pylori infection}

Endoscopy was performed according to standard procedures after an overnight fast. Histological assessment was made of $H$. pylori infection. Biopsy specimens were taken from the greater curve of the antrum. They were fixed overnight in buffered formalin, embedded in paraffin, cut to a thickness of $3 \mu \mathrm{m}$, and stained with hematoxylin-eosin (H\&E) and modified Giemsa stain.

\section{Statistical analysis}

SPSS version 18 (SPSS, Chicago, IL, USA) was used for statistical analyses. Multivariate and univariate logistic regression was performed to investigate the relationship between $H$. pylori status and variables. $\mathrm{P}<0.05$ was considered statistically sig- 
nificant. Odds ratios (OR) and 95\% confidence intervals (CI) were calculated for demographic factors.

\section{Results}

\section{Prevalence of $H$. pylori infection in dyspeptic patients}

Table 1 shows the prevalence of $H$. pylori infection according to socio-demographic characteristics of the study population. Among 303 patients, 263 (86.8\%) were found to be $H$. pylori-positive. There was no difference in prevalence of $H$. pylori infection according to gender. There was no statistically significant association between the prevalence of $H$. pylori infection and other patient demographic factors, such as education status or ethnic group. The prevalence of $H$. pylori infection decreased with age (Figure 1). When the patients were divided into two groups according to age ( $<39 v s \geq 40$ years), the younger group showed a significantly higher prevalence than the older group $(\mathrm{P}=0.01)$. There was no difference in prevalence of $H$. pylori infection between the patients with or without a family history of gastroduodenal diseases $(\mathrm{P}=0.80$ for peptic ulcer, $\mathrm{P}=0.43$ for gastric cancer) (Table 1).

\section{Prevalence of $H$. pylori infection} according to each abdominal symptom

The prevalence of $H$. pylori infection according to each gastrointestinal symptom is shown in Table 2 . Abdominal pain, especially epigastric pain was the most common complaint among dyspepsia. There was no difference in the prevalence of abdominal pain between $H$. pylori-positive and $H$. pylori-negative patients ( $83.3 \%$ vs $77.5 \% ; \mathrm{P}=0.37$ ). There was also no difference in the prevalence of epigastric abdominal pain between $H$. pylori-positive and H. pylori-negative patients $(70.3 \%$ vs $65.0 \%$; $\mathrm{P}=0.49$ ). Interestingly, the prevalence of belching was significantly higher in the $H$. pyloripositive patients than in those who tested negative $(65.0 \%$ vs $47.5 \% ; \mathrm{P}=0.03)$. Even after adjustment for age and gender in the multivariate analysis, $H$. pylori infection was independently associated with the presence of belching $(\mathrm{OR}=2.1,95 \% \mathrm{CI}=1.1-4.3)$. There was no difference in the prevalence of heartburn between $H$. pylori-positive and $H$. pylorinegative patients $(50.2 \%$ vs $37.5 \%$; $\mathrm{P}=0.13)$.

\section{Prevalence of $H$. pylori infection in patients with dyspepsia triggered by diet}

We also examined any possible association between $H$. pylori infection and dyspepsia trig-

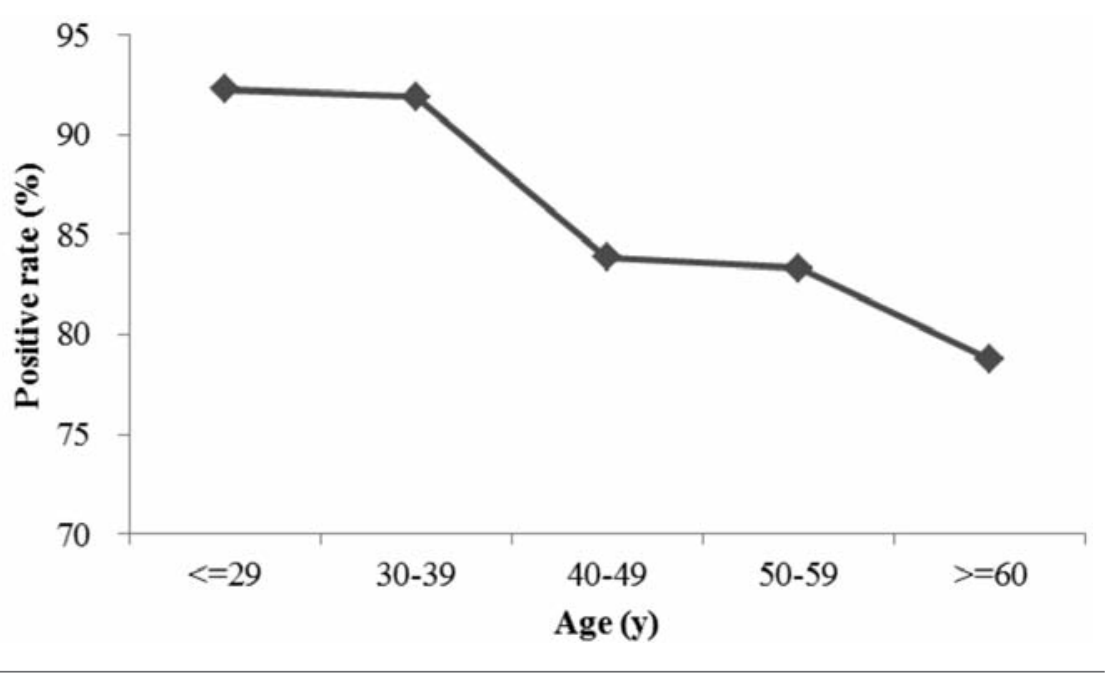

Figure 1. Prevalence of $H$. pylori infection.

Table 1. Comparison of $\boldsymbol{H}$. pylori-positive and -negative dyspeptic patients.

\begin{tabular}{lccc} 
& $\begin{array}{c}\text { H. pylori-positive } \\
(\mathrm{n}=263)\end{array}$ & $\begin{array}{c}\text { H. pylori-negative } \\
(\mathrm{n}=40)\end{array}$ & $\mathrm{P}$ \\
Mean age & $41.5 \pm 15.5$ & $47.0 \pm 14.1$ & 0.02 \\
Male & 113 & 18 & 0.80 \\
\hline Education status & 144 & & \\
$\quad$ High educated & 119 & 16 & 0.53 \\
$\quad$ Low educated & 148 & 21 & \\
Ethnicity & 115 & 19 & 0.65 \\
Fars & & & \\
$\quad$ Other ethnicity & 64 & 9 & 0.80 \\
\hline Family history & 34 & 7 & 0.43 \\
$\quad$ Peptic ulcer & & & \\
Gastric cancer & & & \\
\hline
\end{tabular}

Table 2. Relationship between $\boldsymbol{H}$. pylori status and abdominal symptoms.

\begin{tabular}{lccccc} 
Symptoms & \multicolumn{2}{c}{ H. pylori-positive } & H. pylori-negative & P \\
$(\mathbf{n = 2 6 3 )})$ & 31 & $77.5 \%$ & 0.37 \\
Abdominal pain & 219 & $83.3 \%$ & 26 & $65.0 \%$ & 0.49 \\
Epigastric pain & 185 & $70.3 \%$ & 3 & $7.5 \%$ & 0.59 \\
\hline Other localizations & 31 & $11.8 \%$ & 14 & $35.0 \%$ & 0.78 \\
Anorexia & 98 & $37.3 \%$ & 12 & $30.0 \%$ & 0.65 \\
\hline Weight loss & 70 & $26.6 \%$ & 17 & $42.5 \%$ & 0.28 \\
Nausea & 89 & $33.8 \%$ & 5 & $12.5 \%$ & 0.69 \\
\hline Vomit & 39 & $14.8 \%$ & 15 & $37.5 \%$ & 0.13 \\
Heart burn & 132 & $50.2 \%$ & 17 & $42.5 \%$ & 0.33 \\
\hline Fatty food intolerance & 91 & $34.6 \%$ & 29 & $72.5 \%$ & 0.44 \\
Bloating & 205 & $77.9 \%$ & 19 & $47.5 \%$ & 0.03 \\
\hline Belching & 171 & $65.0 \%$ & 18 & $45.0 \%$ & 0.40 \\
Early satiety & 137 & $52.1 \%$ & 1 & $2.5 \%$ & 1.00 \\
\hline Melena & 7 & $2.7 \%$ & 1 & $2.5 \%$ & 1.00 \\
Dysphagia & 10 & $3.8 \%$ & 18 & $45.0 \%$ & 0.80 \\
\hline Gastric fullness & 113 & $43.0 \%$ & &
\end{tabular}


Table 3. Relationship between H. pylori status and pain triggered by the consumption of diets.

\begin{tabular}{lccccc}
\hline Trigger & H. pylori-positive & H. pylori-negative & P \\
$(\mathrm{n=263)})$ & 0 & $0.0 \%$ & 1.00 \\
Alcohol & 2 & $0.8 \%$ & 0 & $0.0 \%$ & 1.00 \\
Coffee & 4 & $1.5 \%$ & 1 & $2.5 \%$ & 0.01 \\
\hline Tea & 46 & $17.5 \%$ & 0 & $0.0 \%$ & 1.00 \\
Fatty food & 2 & $0.8 \%$ & 4 & $10.0 \%$ & 0.07 \\
\hline Spice & 59 & $22.4 \%$ & 6 & $15.0 \%$ & 0.20 \\
Pepper & 63 & $24.0 \%$ & 16 & $40.0 \%$ & 0.33 \\
\hline Carbonated drink & 85 & $32.3 \%$ & 1 & $2.5 \%$ & 0.48 \\
Smoking & 18 & $6.8 \%$ & 3 & $7.5 \%$ & 0.07 \\
\hline Milk & 50 & $19.0 \%$ & 9 & $22.5 \%$ & 0.99 \\
Raw and fruit and vegitable & 59 & $22.4 \%$ & 0 & $0.0 \%$ & 1.00 \\
\hline Fast food & 2 & $0.8 \%$ & & 0 & \\
\hline
\end{tabular}

gered by diet. The prevalence of dyspepsia triggered by the consumption of tea was significantly higher in the $H$. pylori-positive patients than in those testing negative (17.5 vs $2.5 \%$; $\mathrm{P}=0.01$ ) (Table 3 ). There was no association between consumption of coffee, spicy foods and $H$. pylori status.

\section{Discussion}

Dyspepsia is a common complaint in clinical practice. ${ }^{18}$ Some reports have described that dyspeptic symptoms were more frequent among $H$. pylori-positive patients. ${ }^{19,20}$ Although changes in gastric acid secretion by $H$. pylori infection or functional abnormalities in gastric movement might contribute to dyspepsia, the relationship between them has not been fully clarified. Few reports have described the prevalence of $\mathrm{H}$ pylori with dyspepsia in a hospital setting. In our previous study, over half of the dyspeptic Japanese patients were negative for $H$. pylori. Therefore, factors other than $H$. pylori might play a role in the development of dyspepsia in the hospital setting. ${ }^{21}$ In this study, the prevalence of $H$. pylori infection in dyspeptic patients in Iran was quite high, which means $H$. pylori infection might be related to dyspeptic symptoms. The $H$. pylori infection rate in the Iranian population was reported to be 57-91\%. ${ }^{13-17}$ The prevalence of $H$. pylori infection in patients without dyspepsia would need to be examined in order to prove the relationship. Another way to evaluate the role $H$. pylori in dyspepsia would be to examine the improvement in symptoms after the infection has been cured.

In this study, there was no relationship between $H$. pylori positivity and gender. However some reports have indicated that males were at significant risk for the infection, while other studies indicated that the infection rate was independent of gender. ${ }^{9}$ The prevalence of $H$. pylori was statistically higher in younger patients. Factors such as severe atrophy or intestinal metaplasia mean that the local environment is no longer ideal for the growth of $H$. pylori. This may contribute to the lower prevalence in elderly patients. $H$. pylori infection can be related to low levels of sanitation, hygiene, education. ${ }^{8-10}$ In this study, no relationship was observed between education status and $H$. pylori infection. However, further studies are needed, especially in poor socioeconomic and rural areas.

It has been reported that infection with $H$. pylori can occur in childhood via the fecal-oral route and that it can result in the development of gastroduodenal diseases. ${ }^{22,23}$ Therefore, $H$. pylori infection in individuals with a family history can increase the risk of developing gastroduodenal diseases. In our study, we did not observe any relationship between $H$. pylori infection and family history. Future studies are needed to examine the differences between strains of $H$. pylori concerning the effect of virulence factors in $H$. pylori-related diseases.

There was no association between $H$. pylori status and specific symptoms except for belching. This may be due to the high prevalence of H. pylori. There is little evidence of a relationship between dyspepsia and other symptoms, such as belching, and $H$. pylori infection. Strauss et al..$^{24}$ and Rokkas et al..$^{25}$ found a link between $H$. pylori and postprandial bloating and belching, while others report a relationship between $H$. pylori infection and gastrointestinal symptoms. ${ }^{26-29}$

The prevalence of $H$. pylori in patients with heartburn was $89.7 \%$ which was similar to that of abdominal pain. In general, gasteoesophageal reflux disease and heartburn were common in $H$. pylori-negative patients. ${ }^{21}$ There was also high gastric acid secretion in
H. pylori negative patients. ${ }^{30}$ Endoscopic evaluation or measurement of output of gastric acid will be needed to clarify the difference.

In this study, dyspepsia triggered by the consumption of tea was significantly higher in $H$. pylori-positive patients. It is possible that tea could trigger dyspepsia in the advanced atrophic gastric mucosa induced by long-term H. pylori infection. A population-based study from Iran showed that consumption of hot and strong tea was an independent risk factor for gastric cancer. ${ }^{31}$ Cellular damage induced by consumption of hot tea may explain this association. Consumption of hot food may play a role in the development of gastric cancer due to thermal irritation. ${ }^{32}$ However, one study showed that green tea inhibits $H$. pylori growth in vivo and in vitro. 33 Further study is necessary to clarify these mechanisms.

In conclusion, the prevalence of $H$. pylori infection in dyspeptic patients in an Iranian population was quite high. To prove the significance of $H$. pylori infection in dyspeptic symptoms, it will be necessary to evaluate the improvement of symptoms after $H$. pylori eradication.

\section{References}

1. Marshall B, Warren J. Unidentified curved bacilli in the stomach of patients with gastritis and peptic ulceration. Lancet 1984;1: 1311-5.

2. Bayerdörffer E, Neubauer A, Rudolph B, et al. Regression of primary gastric lymphoma of mucosa-associated lymphoid tissue type after cure of Helicobacter pylori infection. MALT Lymphoma Study Group. Lancet 1995;345:1591-4.

3. Parsonnet J, Friedman GD, Vandersteen DP, et al. Helicobacter pylori infection and the risk of gastric carcinoma. N Engl J Med 1991;325:1127-314. Rothenbacher D, Inceoglu J, Bode G, Brenner H. Acquisition of Helicobacter pylori infection in a highrisk population occurs within the first 2 years of life. J Pediatr 2000;136:744-8.

5. Dominici P, Bellentani S, Di Biase AR, et al. Familial clustering of Helicobacter pylori infection: population based study. BMJ 1999;319:537-40.

6. Escobar ML, Kawakami E. Evidence of mother-child transmission of Helicobacter pylori infection. Arq Gastroenterol. 2004; 41:239-44.

7. Lindkvist P, Asrat D, Nilsson I, et al. Age at acquisition of Helicobacter pylori infection: comparison of a high and a low prevalence country. Scand J Infect Dis 1996;28: 181-4.

8. Shinchi K, Ishii H, Imanishi K, Kono S. Relationship of cigarette smoking, alcohol 
use, and dietary habits with Helicobacter pylori infection in Japanese men. Scand J Gastroenterol 1997;32:651-5.

9. Replogle ML, Glaser SL, Hiatt RA, Parsonnet J. Biologic sex as a risk factor for Helicobacter pylori infection in healthy young adults. Am J Epidemiol 1995;142: 856-63.

10. Goh KL. Prevalence of and risk factors for Helicobacter pylori infection in a multiracial dyspeptic Malaysian population undergoing endoscopy. J Gastroenterol Hepatol 1997;12:S29-35.

11. Asaka M, Kimura T, Kudo M, et al. Relationship of Helicobacter pylori to serum pepsinogens in an asymptomatic Japanese population. Gastroenterology 1992;102:760-6.

12. Shiota S, Murakami K, Fujioka T, Yamaoka Y. Population-based strategies for Helicobacter pylori-associated disease management: a Japanese perspective. Expert Rev Gastroenterol Hepatol 2010;4:149-56.

13. Malekzadeh R, Sotoudeh M, Derakhshan $\mathrm{MH}$, et al. Prevalence of gastric precancerous lesions in Ardabil, a high incidence province for gastric adenocarcinoma in the northwest of Iran. J Clin Pathol 2004; 57:37-42.

14. Britt DP, Barakat MH, Tungekar MF, et al. Helicobacter pylori in dyspeptic patients in Kuwait. J Clin Pathol 1990;43:987-91.

15. Alborzi A, Soltani J, Pourabbas B, et al. Prevalence of Helicobacter pylori infection in children (south of Iran). Diagn Microbiol Infect Dis 2006;54:259-61.

16. Baghaei K, Shokrzadeh L, Jafari F, et al. Determination of Helicobacter pylori virulence by analysis of the cag pathogenicity island isolated from Iranian patients. Dig
Liver Dis 2009;41:634-8.

17. Shokrzadeh L, Baghaei K, Yamaoka Y, et al. Analysis of 3'-end variable region of the cagA gene in Helicobacter pylori isolated from Iranian population. J Gastroenterol Hepatol 2010;25:172-7.

18. Talley N, Zinsmeister A, Schleck C, Melton LJ 3rd. Dyspepsia and dyspepsia subgroups: a population-based study. Gastroenterology 1992;102:1259-68.

19. Shimatani T, Inoue $\mathrm{M}$, Iwamoto $\mathrm{K}$, et al. Prevalence of Helicobacter pylori infection, endoscopic gastric findings and dyspeptic symptoms among a young Japanese population born in the $1970 \mathrm{~s}$. J Gastroenterol Hepatol 2005;20:1352-7.

20. Rosenstock S, Kay L, Rosenstock C, et al. Relation between Helicobacter pylori infection and gastrointestinal symptoms and syndromes. Gut 1997;41:169-76.

21. Shiota S, Murakami K, Takayama A, et al. Evaluation of Helicobacter pylori status and endoscopic findings among new outpatients with dyspepsia in Japan. J Gastroenterol 2009;44:930-4.

22. Naficy AB, Frenck RW, Abu-Elyazeed R, et al. Seroepidemiology of Helicobacter pylori infection in a population of Egyptian children. Int J Epidemiol 2000;29:928-32.

23. Rothenbacher D, Winkler M, Gonser T, et al. Role of infected parents in transmission of helicobacter pylori to their children. Pediatr Infect Dis J 2002;21:674-9.

24. Strauss R, Wang T, Kelsey P, et al. Association of Helicobacter pylori infection with dyspeptic symptoms in patients undergoing gastroduodenoscopy. Am J Med 1990;89:464-9.

25. Rokkas T, Pursey C, Uzoechina E, et al. Campylobacter pylori and non-ulcer dyspepsia. Am J Gastroenterol 1987;82:1149-
52.

26. Holtmann G, Goebell H, Holtmann M, Talley NJ. (1994) Dyspepsia in healthy blood donors. Pattern of symptoms and association with Helicobacter pylori. Dig Dis Sci 1994;39:1090-8.

27. Braden B, Caspary WF, Lembcke B. Density of gastric Helicobacter pylori colonization is not associated with occurrence of dyspeptic symptoms. Dig Dis Sci 1997;42:2120-3.

28. Caballero-Plasencia AM, Muros-Navarro MC, Martín-Ruiz JL, et al. (1995) Dyspeptic symptoms and gastric emptying of solids in patients with functional dyspepsia. Role of Helicobacter pylori infection. Scand J Gastroenterol 1995;30:74551.

29. Marzio L, Cappello G, Ballone E. Evaluation of dyspeptic symptoms in patients with and without Helicobacter pylori infection and normal upper gastrointestinal endoscopy. Dig Liver Dis 2003;35:138-42.

30. Delaney B, McColl K. Review article: Helicobacter pylori and gastrooesophageal reflux disease. Aliment Pharmacol Ther 2005;22:32-40.

31. Pourfarzi F, Whelan A, Kaldor J, Malekzadeh R. The role of diet and other environmental factors in the causation of gastric cancer in Iran--a population based study. Int J Cancer 2009;125:1953-60.

32. La Vecchia C, Negri E, D'Avanzo B, Franceschi S. Food temperature and gastric cancer. Int J Cancer 1990;46:432-4.

33. Stoicov C, Saffari R, Houghton J. Green tea inhibits Helicobacter growth in vivo and in vitro. Int J Antimicrob Agents 2009;33:4738. 